\title{
Una reseña de Prueba de Evaluación de Conciencia Fonológica (PECFO)
}

\section{A review of Phonological Awareness Test}

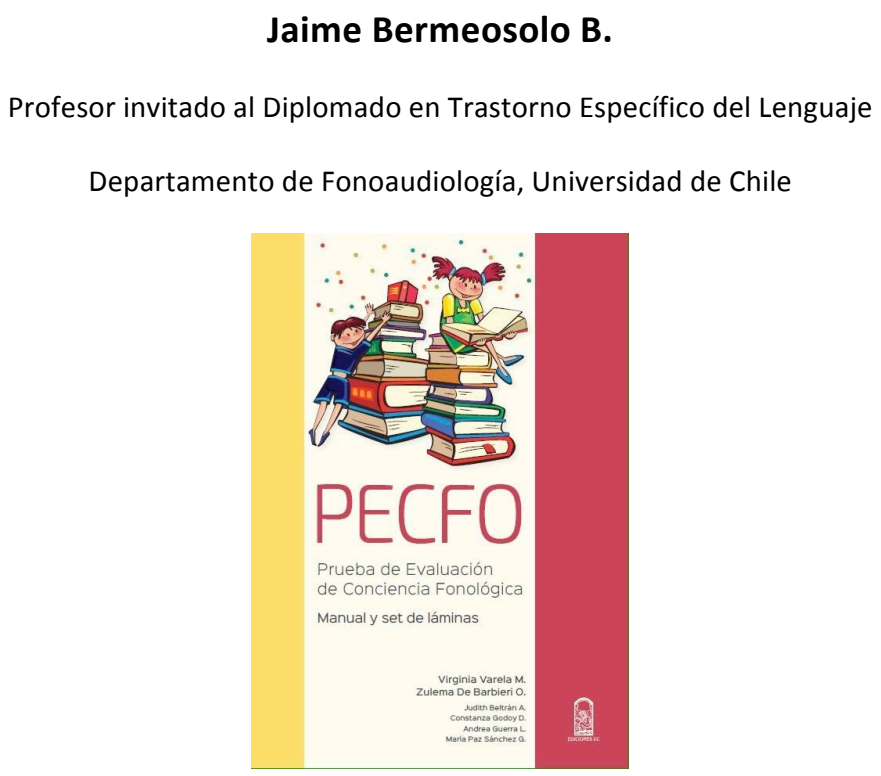

Autor: Virginia Varela M. y Zulema De Barbieri O.

Colaboran: Judith Beltrán A., Constanza Godoy D., Andrea Guerra L. y María Paz Sánchez G.

Editorial: Ediciones Universidad Católica de Chile

Número de páginas: 105 páginas

Año: 2015

Datos autor: Ambas autoras son fonoaudiólogas y académicas del Departamento de Fonoaudiología de la Facultad de Medicina, Universidad de Chile.

Una nueva prueba dentro del vasto campo de la evaluación del lenguaje entrega el equipo de la Departamento de Fonoaudiología de la Facultad de Medicina de la Universidad de Chile a quienes se 
desempeñan en áreas, tales como la didáctica del lenguaje inicial, el aprendizaje de la lectura y escritura, psicolingüística evolutiva y las alteraciones del lenguaje y la comunicación.

El instrumento se denomina Prueba de Evaluación de Conciencia Fonológica (PECFO) y está destinado a estimar el desempeño en dicha habilidad en niños de 4.0 a 8.0 años (más precisamente, 4.0 a 7 años 11 meses). Pretende detectar el grado de madurez del niño en la habilidad metafonológica relacionada con la identificación de sílabas y fonemas. Explican las autoras:

Dada la importancia que tiene el desarrollo de esta habilidad metalingüística es fundamental determinar el nivel de conocimiento fonológico de un niño, para poder intervenir de manera oportuna minimizando el impacto negativo que pueda tener sobre el aprendizaje del lenguaje escrito.

Ambas autoras y docentes son fonoaudiólogas formadas en la Universidad de Chile. Tienen grado de Magíster: Virginia Varela, en Psicología Clínica y Zulema de Barbieri en Educación Especial. Virginia es, además, psicóloga. Las dos, junto con sus actividades académicas en pre y posgrado, participan en varios proyectos de investigación y cuentan con una serie de publicaciones. Colaboraron en las diferentes etapas de investigación que dieron pie al instrumento varias alumnas de la carrera de fonoaudiología y algunas fonoaudiólogas. Se destaca en el manual la participación de Judith Beltrán A., Constanza Godoy D., Andrea Guerra L. y María Paz Sánchez.

Los materiales de la prueba consisten en el manual, de atractiva presentación y cuidadosa diagramación, incluyendo un set de láminas, y el folleto de aplicación individual con instrucciones para la aplicación y hojas de registro. En el manual, los usuarios encontrarán información acerca de los fundamentos teóricos y descripción del instrumento, así como los detalles relativos a la aplicación, las tablas con las normas (en percentiles) e interpretación de los resultados. Se incluye un par de ejemplos concretos de aplicación que, de acuerdo con los resultados, afectan notoriamente las decisiones a tomar con el niño en cuestión.

El test contempla dos secciones: la primera, relacionada con la conciencia de la sílaba, consta de seis subpruebas. La segunda, relacionada con la conciencia del fonema, consta de cuatro. Es de aplicación individual y el tiempo requerido es de unos veinte minutos. Por cierto, el examinador debe estar familiarizado con las características de la prueba, la nominación de los dibujos, el registro, análisis e interpretación de los resultados.

Subpruebas de la primera sección son las de segmentación silábica, identificación de la sílaba inicial, identificación de la sílaba final, omisión de la sílaba inicial, omisión de la sílaba final, e inversión silábica. En la segunda sección, se incluyen las de identificación del fonema inicial, identificación del fonema final, omisión del fonema inicial y síntesis fonémica. Se detallan en el manual los criterios que 
llevaron a la elección de las palabras, todas ellas del vocabulario activo de los niños de 4 a 7 años, su metría, el tipo de sílabas que las conforman, etc. Cada ítem dentro de la subprueba se compone normalmente de cuatro imágenes: la primera corresponde al estímulo referente y las otras tres a la respuesta, de las cuales dos son distractores.

El examinador debe mostrar los dibujos para cada ítem, nominándolos uno a uno, a fin de evitar problemas en la interpretación de las figuras (algunas pueden admitir más de una nominación: "pelota" podría ser interpretada como "balón", denominación que no sirve para los propósitos del subtest). El niño debe limitarse a mostrar la respuesta que cree correcta, no necesita decirla, por lo cual la prueba puede ser utilizada sin problemas con niños con dificultades de lenguaje.

El capítulo del manual dedicado al análisis estadístico del instrumento da cuenta detallada de las características de la muestra de aplicación, estudios de validez y estimaciones de la confiabilidad. Se trata de un instrumento válido y confiable que, al alero de Ediciones Universidad Católica de Chile, tendrá posibilidades de confirmar sus méritos a lo largo del país, en el que -es cierto-, ya existen algunas pruebas dedicados al tema, pero de carácter muy local y sin los estudios y antecedentes que avalan la que están entregando las autoras.

Un par de reflexiones pueden servir para entender mejor la necesidad de un instrumento como el que estamos presentando.

La primera tiene que ver con el aprendizaje de la lengua escrita por parte del niño. Nuestro sistema de escritura es de tipo "fonográfico", ya que representa directamente la cadena hablada o expresión oral, y no logográfico o ideográfico, que representan con un símbolo o dibujo convencional palabras enteras o conceptos. Además es "alfabético" y no silábico, ya que representa sonidos que corresponden gruesamente a las letras del alfabeto, es decir, los fonemas, unidades constituyentes de las palabras, menores que las sílabas y que marcan diferencias en el significado. Hay sistemas "silábicos", en que cada sílaba completa se representa con un signo, lo que no ocurre en español (a excepción de las sílabas formadas por fonemas vocálicos). Ello obliga necesariamente a "tomar conciencia" de los fonemas los que, aparte de los vocálicos /a/ /e/ /i/ /o/ / /, no tienen "existencia real" independiente en el habla. Los vocálicos, como se acaba de explicar, pueden constituir cada uno de ellos una sílaba o, incluso, una palabra (por ejemplo, conjunciones).

Los fonemas consonánticos $(/ \mathrm{s} / / \mathrm{k} / / \mathrm{p} /$, etc.) solo se realizan en español en la sílaba, acompañando a la vocal. ¡El niño tendrá que darse cuenta, por tanto, de que las sílabas (y a la vez palabras, en estos ejemplos) "sol" "pan" y "sin", que se pronuncian con "un solo golpe de voz" cada una, deben escribirse con tres letras y no con una! De esta manera, al tener que poner por escrito palabras al dictado como "mamá", "auto" o "tren", tendrá que tener conciencia de sus 
constituyentes, o no podrá hacerlo, salvo que haya aprendido algunas de tales palabras memorísticamente como una totalidad o un "logograma". Esta conciencia "metafonológica", que es lo que mide el test, es fundamental para la lectura y escritura, y forma parte de la conciencia metalingüística. Más adelante el niño tendrá que aprender, por ejemplo, que las palabras (o conceptos) deberán ir separadas por espacios en blanco en la escritura, pese a que en la cadena hablada o expresión oral se articulan "pegadas" unas a otras.

Con estos antecedentes, quienes no están familiarizados con estas cuestiones, como estudiantes universitarios de pregrado que comienzan a estudiar la lengua o personas que quieran enseñar a leer y escribir, comprenderán de mejor forma la definición de las autoras:

La conciencia fonológica es una habilidad metafonológica que se entiende como la capacidad del sujeto para identificar y manipular los distintos segmentos de la palabra hablada, permitiéndoles percibir la existencia de sonidos individuales, separando los enunciados en subunidades menores y utilizando estas últimas para formar nuevas unidades superiores. La importancia de esta habilidad, que se desarrolla aproximadamente entre los 4 y 7 años de edad, es que es el predictor más importante del aprendizaje de la lecto-escritura, en especial en la decodificación durante la etapa de la lectura inicial.

La segunda reflexión dice relación con la representación de nuestros conocimientos en los sistemas de registro de largo plazo, que oscilan entre lo "procedimental" y lo "declarativo". Las memorias y conocimientos procedimentales, con un fuerte componente motor, tienen que ver con nuestras habilidades y rutinas de la vida diaria, automatizadas, y que no exigen control consciente. Se les identifica con el aprendizaje y conocimiento "implícitos", término que hace referencia a que no puede accederse a ellos con facilidad mediante la introspección y a que no resulta fácil expresarlos con palabras: suelen ser característicos de la adquisición de destrezas como andar en bicicleta, silbar, y también hablar y realizar muchas rutinas mentales. El niño utiliza desde temprano estructuras gramaticales cada vez más complejas, gracias a la preparación de la especia humana para el lenguaje, lo que sorprende en relación con su capacidad de insight. Pese a ese notable talento, es incapaz de explicar las reglas subyacentes. Estas deberán enseñársele explícitamente a lo largo de su escolaridad, pudiendo así llegar a formar parte de su conocimiento "declarativo". La escolaridad exige hacer explícitas las tareas que el niño realiza fluidamente, entre ellas hablar, para poder "declararlas". De esa manera -y aquí reside su importancia- se puede influir en ellas para perfeccionarlas y transferirlas a otras situaciones o dominios. Es lo que ocurre con la conciencia metafonológica y la conciencia metalingüística en general. Por otra parte, en sentido contrario, el desarrollo de destrezas y habilidades supone el tránsito desde una codificación inicial de la tarea en términos declarativos, 
explícitos, hasta llegar finalmente a su codificación procedimental: el maestro, el instructor, el terapeuta, explican la tarea, y el alumno, el paciente, la van llevando a cabo, siguiendo la secuencia de pasos propuesta, hasta automatizarla o "procedimentarla" a través de la práctica reiterada y la ejercitación.

Las dos reflexiones anteriores pueden servir para valorar la importancia de contribuciones como la de la Prueba de Evaluación de Conciencia Fonológica (PECFO) a la labor profesional de educadores especiales, psicopedagogos y fonoaudiólogos, entre otros. 